\title{
Growth factor receptor-Src-mediated suppression of GRK6 dysregulates CXCR4 signaling and promotes medulloblastoma migration
}

Liangping Yuan ${ }^{1}$, Hongying Zhang ${ }^{1}$, Jingbo Liu', Joshua B Rubin², Yoon-Jae Cho ${ }^{3}$, Hui Kuo Shu ${ }^{4}$, Matthew Schniederjan ${ }^{5}$ and Tobey J MacDonald ${ }^{1 *}$

\begin{abstract}
Background: Metastasis in medulloblastoma (MB) is associated with poor survival. Recent genetic studies revealed MB to comprise distinct molecular subgroups, including the sonic hedgehog $(\mathrm{SHH})$ subgroup that exhibits a relatively high rate of progression. To identify targeted therapeutics against metastasis, a better understanding of the regulation of $\mathrm{MB}$ cell migration is needed. G protein-coupled receptor kinases (GRKs) have been implicated in cancer metastasis through their regulation of G-protein coupled receptors (GPCRs) involved in growth factor (GF)-mediated cell migration. However, the specific roles and regulation of GRKs in MB have not been investigated.

Methods: Microarray mRNA analysis was performed for GRKs, GPCRs, and GFs in 29 human MB, and real time RT-PCR was used to detect GRK6 expression in MB cells. Lenti- or retro-virus infection, and siRNA or shRNA transfection, of MB cells was used to overexpress and knockdown target genes, respectively. Western blot was used to confirm altered expression of proteins. The effect of altered target protein on cell migration was determined by Boyden chamber assay and XCELLigence migration assays.

Results: We observed co-overexpression of PDGFRA, CXCR4, and CXCL12 in the SHH MB subtype compared to non$\mathrm{SHH} M B(5,7$, and 5-fold higher, respectively). GRK6, which typically acts as a negative regulator of CXCR4 signaling, is downregulated in $\mathrm{MB}$, relative to other GRKs, while the percentage of GRK6 expression is lower in MB tumors with metastasis (22\%), compared to those without metastasis (43\%). In SHH-responsive MB cells, functional blockade of PDGFR abolished CXCR4-mediated signaling. shPDGFR transfected MB cells demonstrated increased GRK6 expression, while PDGF or 10\% FBS treatment of native MB cells reduced the stability of GRK6 by inducing its proteosomal degradation. Overexpression or downregulation of Src, a key mediator of GF receptor/PDGFR signaling, similarly inhibited or induced GRK6 expression, respectively. siRNA downregulation of GRK6 enhanced CXCR4 signaling and promoted MB migration, while lentiviral-GRK6 overexpression suppressed CXCR4 signaling, potentiated the effect of AMD3100, a CXCR4 antagonist, and impaired migration.
\end{abstract}

Conclusions: Our findings demonstrate a novel mechanism of GF receptor/PDGFR-Src-mediated dysregulation of CXCR4 signaling that promotes MB cell migration, which could potentially be exploited for therapeutic targeting in SHH MB.

Keywords: GRK6, CXCR4, Growth factor receptor, PDGFR, Src, Medullobastoma

\footnotetext{
* Correspondence: tobey.macdonald@emory.edu

${ }^{1}$ Department of Pediatrics, Aflac Cancer and Blood Disorders Center, Emory University School of Medicine, 2015 Uppergate Drive NE, Atlanta, GA 30322, USA

Full list of author information is available at the end of the article
} 


\section{Background}

Medulloblastoma (MB) is the most common malignant brain tumor of childhood, and for those with metastasis the prognosis is typically poor [1]. The molecular sub-types of MB have different rates of metastasis, but to date, no clearly defined genetic alteration has been linked to the initiation of metastasis [2-4]. As such, all children with $\mathrm{MB}$ receive craniospinal irradiation to treat or protect against the development of metastasis. This treatment is suboptimal and results in excessive neurocognitive morbidity [1]. Thus, identifying the mechanisms of $\mathrm{MB}$ migration will provide invaluable insight into $\mathrm{MB}$ progression, which ultimately should lead to more effective and less toxic therapeutics for its prevention.

Activation of growth factor (GF) receptor signaling has been implicated in promoting cancer metastasis. Our previous studies described overexpression of the platelet-derived growth factor receptor (PDGFR) in association with metastatic $\mathrm{MB}$, and demonstrated that PDGFR promotes migration through ERK-dependent activation of p21 protein (Cdc42/Rac)-activated kinase 1 (Pak1) signaling [5,6]. More recently, PDGFR overexpression was detected in both the primary and matched metastatic tumors derived from mouse models of MB [7]. Given the prominent association of PDGFR with $\mathrm{MB}$ metastasis, we hypothesized that GF receptor signaling, such as that by PDGFR, may also dysregulate other GF-mediated pathways as a mechanism to potentiate cell migration. One such candidate is the chemokine receptor CXCR4, a member of the G protein-coupled receptor (GPCR) family that is closely associated with PDGFR-expressing progenitor cells [8-11]. CXCR4 plays critical roles in the proliferation and migration of granule cell neuron precursors during development, and is involved in cancer metastasis [12-14]. Human stromal cell-derived factor-1 $\alpha$ (SDF-1 $\alpha$, also known as CXCL12), binds CXCR4 and activates Gai-mediated signaling [15]. Upon CXCL12 binding, CXCR4 dimerizes, and is in turn phosphorylated, which induces its internalization and lysosomal degradation resulting in signal termination [15]. Increased CXCR4 expression is associated with aggressive cancer behavior [16]. Cho et al. reported that the MB subgroups molecularly defined as $\mathrm{c} 1$ and $\mathrm{c} 3$ /sonic hedgehog $(\mathrm{SHH})$ are responsible for the majority of relapses and death due to $\mathrm{MB}$ progression and that CXCR4 is a marker for the $\mathrm{c} 3 / \mathrm{SHH}$ subgroup [17]. A recent study confirmed that $\mathrm{SHH}$ signaling is required for CXCR4 activation [18]. The desmoplastic variant of medulloblastoma, characterized by the presence of abundant connective tissue, belongs almost exclusively to the $\mathrm{SHH}$ subgroup and makes up about $50 \%$ of $\mathrm{SHH} \mathrm{MB}$, but predominantly occurs in children less than 3 years of age. Interestingly, $\mathrm{SHH} \mathrm{MB}$ with desmoplastic histology has a favorable prognosis, whereas non-desmoplastic $\mathrm{SHH} \mathrm{MB}$ has higher rates of metastasis and an intermediate prognosis [4]. This dichotomy suggests that additional modulators of $\mathrm{SHH}$ CXCR4 activity may determine MB clinical behavior.

$G$ protein-coupled receptor kinases (GRKs) mediate phosphorylation-dependent GPCR internalization and desensitization controlling GPCR activity $[19,20]$. GRKs selectively phosphorylate activated receptors, promoting high affinity binding of arrestins, which precludes G protein coupling [21,22]. GRKs are divided into three subfamilies: GRK1 (GRK 1 and 7), GRK2 (GRK 2 and 3), and GRK4 (GRK 4, 5 and 6) [23]. Regulation of GPCRs is cell-and GRK-specific. For example, in HEK293 cells, GRK3 and GRK6 promote CXCR4-mediated ERK1/2 activation [15]. However, in HeLa cells, GRK6 induces CXCR4 internalization and inhibits ERK1/2 activation [24]. Similarly, T cells from GRK6-deficient animals are unable to migrate in response to CXCL12 [25], while GRK6 loss in neutrophils enhances CXCL12-induced migration [26]. Evidence indicates that GRK activity is tightly regulated through protein interactions (e.g. Akt or MAPK) that modulate GRK stability [27]. We thus hypothesized that similar mechanisms exist in $\mathrm{MB}$, and report here that GRK-dependent CXCR4 activity is dysregulated by GF receptor/PDGFR-Src signaling resulting in the promotion of $\mathrm{MB}$ cell migration.

\section{Results}

Overexpression of CXCL12 and CXCR4 correlates with SHH MB and PDGFR activity is required for optimal CXCR4 signaling in SHH MB cells

Because of the dichotomy of clinical outcomes observed for $\mathrm{SHH} \mathrm{MB}$, we first investigated whether the expression profiles of CXCL12 and CXCR4 in SHH and non-SHH $\mathrm{MB}$ is associated with tumor histology (desmoplastic vs. non-desmoplastic) and clinical outcome. We performed microarray RNA analysis on 29 primary human MB specimens and analyzed the gene expression of members of the $\mathrm{SHH}$ pathway (to determine $\mathrm{SHH}$ from nonSHH MB), CXCL12 and CXCR4. In our cohort, 11/29 (38\%) MB analyzed are $\mathrm{SHH}$-active, and the mean age in $\mathrm{SHH}$ and non-SHH tumors is 3.7 and 6.4 years, respectively, which are consistent with the frequency and age distributions observed in historical MB populations [1-4]. The percentage of desmoplastic tumors in our cohort $(10 \%)$ is also consistent with the distribution observed in childhood MB. Consistent with reports by others [2], all of the desmoplastic tumors in our cohort are $\mathrm{SHH} \mathrm{MB}$, with desmoplastic tumors representing $27 \%$ of the SHH MB (Table 1). All SHH tumors demonstrate co-overexpression of CXCL12 and CXCR4, with the exception of one tumor that was obtained after treatment with high-dose chemotherapy. None of the 
Table 1 mRNA Expression Profile of CXCR4 and CXCL12 in SHH vs. non-SHH MB

\begin{tabular}{|c|c|c|c|c|c|c|}
\hline $\begin{array}{l}\text { Tumor } \\
\text { histology }\end{array}$ & $\begin{array}{l}\text { Collection of } \\
\text { specimen }\end{array}$ & $\begin{array}{l}\text { Patient age at time of } \\
\text { specimen collection }\end{array}$ & $\begin{array}{l}\text { Patient } \\
\text { status }\end{array}$ & SHH or Non-SHH & $\begin{array}{l}\text { CXCR4 relative } \\
\text { mRNA level }\end{array}$ & $\begin{array}{l}\text { CXCL12 relative } \\
\text { mRNA level }\end{array}$ \\
\hline Desmoplastic & Diagnostic & 1 year & DECEASED & $\mathrm{SHH}$ & 5422 & 1631 \\
\hline Desmoplastic & Diagnostic & 2 years & ALIVE & $\mathrm{SHH}$ & 1745 & 217 \\
\hline Desmoplastic & Diagnostic & 5 years & ALIVE & $\mathrm{SHH}$ & 6036 & 1707 \\
\hline Anaplastic & Post-Rx & 3 years & DECEASED & $\mathrm{SHH}$ & 1216 & 10 \\
\hline Classic & Diagnostic & 9 months & ALIVE & $\mathrm{SHH}$ & 6225 & 356 \\
\hline Clssic & Diagnostic & 1 year & DECEASED & $\mathrm{SHH}$ & 2050 & 567 \\
\hline Classic, & Diagnostic & 2 years & DECEASED & $\mathrm{SHH}$ & 3175 & 909 \\
\hline Classic & Post-Rx & 2 years & DECEASED & $\mathrm{SHH}$ & 4529 & 623 \\
\hline Classic & Diagnostic & 4 years & ALIVE & $\mathrm{SHH}$ & 3864 & 463 \\
\hline Classic & Diagnostic & 5 years & ALIVE & $\mathrm{SHH}$ & 4408 & 149 \\
\hline \multirow[t]{2}{*}{ Classic, M+ } & Post-Rx & 7 years & DECEASED & $\mathrm{SHH}$ & 911 & 2222 \\
\hline & & & & Mean \pm SD & $3598 \pm 1915$ & $805 \pm 730$ \\
\hline MBEN & Diagnostic & 3 years & ALIVE & Non-SHH & 138 & 291 \\
\hline Anaplastic & Diagnostic & 2 years & ALIVE & Non-SHH & 43 & 48 \\
\hline Anaplastic & Diagnostic & 6 years & ALIVE & Non-SHH & 1717 & 76 \\
\hline Classic & Diagnostic & 6 months & ALIVE & Non-SHH & 4367 & 20 \\
\hline Classic & Diagnostic & 1 year & ALIVE & Non-SHH & 339 & 200 \\
\hline Classic & Diagnostic & 2 years & ALIVE & Non-SHH & 107 & 1144 \\
\hline Classic & Diagnostic & 2 years & ALIVE & Non-SHH & 240 & 615 \\
\hline Classic & Diagnostic & 2 years & ALIVE & Non-SHH & 582 & 13 \\
\hline Classic & Diagnostic & 3 years & ALIVE & Non-SHH & 193 & 92 \\
\hline Classic & Diagnostic & 5 years & DECEASED & Non-SHH & 185 & 75 \\
\hline Classic & Diagnostic & 6 years & DECEASED & Non-SHH & 125 & 62 \\
\hline Classic & Diagnostic & 6 years & ALIVE & Non-SHH & 28 & 43 \\
\hline Classic, M+ & Diagnostic & 8 years & DECEASED & Non-SHH & 198 & 116 \\
\hline Classic & Diagnostic & 11 years & ALIVE & Non-SHH & 73 & 47 \\
\hline Classic & Diagnostic & 11 years & ALIVE & Non-SHH & 51 & 59 \\
\hline Classic & Diagnostic & 11 years & ALIVE & Non-SHH & 374 & 55 \\
\hline Classic & Diagnostic & 12 years & ALIVE & Non-SHH & 69 & 149 \\
\hline \multirow[t]{3}{*}{ Classic } & Diagnostic & 16 years & ALIVE & Non-SHH & 80 & 73 \\
\hline & & & & Mean \pm SD & $495 \pm 1041$ & $177 \pm 280$ \\
\hline & & & & $\begin{array}{l}\text { Fold change SHH/ } \\
\text { Non-SHH }\end{array}$ & $+7 X$ & $+5 X$ \\
\hline \multicolumn{7}{|c|}{ SHH MB desmoplastic vs. Non-desmpplastic } \\
\hline Desmoplastic & Diagnostic & 1 year & DECEASED & $\mathrm{SHH}$ & 5422 & 1631 \\
\hline Desmoplastic & Diagnostic & 2 years & ALIVE & $\mathrm{SHH}$ & 1745 & 217 \\
\hline \multirow[t]{2}{*}{ Desmoplastic } & Diagnostic & 5 years & ALIVE & $\mathrm{SHH}$ & 6036 & 1707 \\
\hline & & & & Mean \pm SD & $4401 \pm 2321$ & $1185 \pm 839$ \\
\hline Anaplastic & Post-Rx & 3 years & DECEASED & $\mathrm{SHH}$ & 1216 & 10 \\
\hline Classic & Diagnostic & 9 months & ALIVE & $\mathrm{SHH}$ & 6225 & 356 \\
\hline Classic & Diagnostic & 1 year & DECEASED & $\mathrm{SHH}$ & 2050 & 567 \\
\hline Classic & Diagnostic & 2 years & DECEASED & $\mathrm{SHH}$ & 3175 & 909 \\
\hline Classic & Diagnostic & 2 years & DECEASED & $\mathrm{SHH}$ & 4529 & 623 \\
\hline Classic & Diagnostic & 4 years & ALIVE & $\mathrm{SHH}$ & 3864 & 463 \\
\hline
\end{tabular}


Table 1 mRNA Expression Profile of CXCR4 and CXCL12 in SHH vs. non-SHH MB (Continued)

\begin{tabular}{|c|c|c|c|c|c|c|}
\hline Classic & Diagnostic & 5 years & ALIVE & $\mathrm{SHH}$ & 4408 & 149 \\
\hline \multirow[t]{2}{*}{ Classic, M+ } & Post-Rx & 7 years & DECEASED & $\mathrm{SHH}$ & 911 & 2222 \\
\hline & & & & Mean \pm SD & $3297 \pm 1822$ & $662 \pm 689$ \\
\hline
\end{tabular}

SHH MB, sonic-hedgehog medulloblastoma; $M B E N$, medulloblastoma with extensive nodularity; $M+$, metastatic; Post-Rx, post-treatment.

non-SHH MB display co-overexpression, and only two non-SHH MB demonstrate relative overexpression of CXCR4 (Table 1). Compared to non-SHH MB, the relative mean expression of CXCR4 and CXL12 in SHH MB is 7 - and 5 -fold higher, respectively (Table 1$)(\mathrm{P}<0.01$ and $\mathrm{P}<0.05)$, respectively). We also examined the expression of PDGFR pathway members for correlations with $\mathrm{SHH} \mathrm{MB}$ and found that although PDGFRA overexpression is observed in $\sim 50 \%$ of the non- $\mathrm{SHH}$ $\mathrm{MB}$, the relative mean expression level for PDGFRA is 5 -fold higher in SHH MB $(\mathrm{P}<0.01)$, and PDGF-A, which only binds to PDGFRA, is 4-fold higher $(\mathrm{P}<0.01)$, while that of PDGF-D, which only binds PDGFRB, is 3-fold higher $(\mathrm{P}<0.01) \quad$ (Table 2$)$, suggesting that both PDGFRA and PDGFRB are preferentially activated in SHH MB.

Consistent with the report by Cho et al. [17], we observed that a disproportionate number of patients with SHH tumors died of disease. Only 5/11 (45\%) patients with $\mathrm{SHH}$ MB are survivors beyond 5 years from diagnosis compared to $15 / 18(83 \%)$ long-term survivors in the non-SHH group $(\mathrm{P}<0.05$, two-tailed Fisher's exact test), (Table 1). In our cohort, there is no significant difference in $M Y C$ expression between the $\mathrm{SHH}$ and non-SHH MB (SHH MB, $645 \pm 1678$ vs. non-SHH MB, $1032 \pm 1756$, $\mathrm{P}>0.05)$. With the exception of one case, all the deaths in the SHH MB group were of patients with tumors having non-desmoplastic histology. In the SHH MB, there are no obvious differences in the expression levels of CXCR4 or CXCL12 between desmoplastic and nondesmoplastic histology, or between those alive and deceased, although the number of desmoplastic tumors is too small to determine statistical significance. This suggests that if CXCR4 signaling does promote aggressive $\mathrm{MB}$ behavior, then post-transcriptional factors regulating CXCR4 activity, rather than CXCR4 or CXCL12 expression alone, must dictate this clinical phenotype.

Since we found both PDGFR and CXCR4 overexpression in association with SHH MB, and it has been shown that PDGF-D overexpression induces CXCR4 and promotes metastasis in breast cancer cells [14], we postulated that there may be a functional relationship between PDGFR and CXCR4. To test this hypothesis, we used specific antiPDGFR function blocking antibody to treat Daoy $\mathrm{SHH}$ $\mathrm{MB}$ cells for $24 \mathrm{~h}$, then stimulated cells with PDGF and CXCL12. Upon CXCL12 ligand binding, CXCR4 activates ERK1/2, thus, CXCL12-induced phosphorylation of ERK
(P-ERK) is employed as a downstream marker of CXCR4 activation [24]. Our results show that PDGFR blocking antibody abolished not only PDGF-induced P-ERK, as expected, but also CXCL12-induced P-ERK (Figure 1A) $[\mathrm{P}<0.05$, lane $3,1.53 \pm 0.12$ vs. lane $6,1.09 \pm 0.15$ by comparing the densitometry of CXCL12-induced P-ERK/ERK between Daoy cells with or without PDGFR blocking antibody treatment, the ratio of P-ERK/ERK in lane 1 is equal to $1.00(100 \%)$, and the relative changes of ratio of P-ERK/ ERK in other lanes were calculated by dividing by the ratio in lane1], indicating that PDGFR activity is required for activation of CXCL12-CXCR4 signaling in $\mathrm{SHH}-$ responsive $\mathrm{MB}$ cells.

\section{GRK6 is downregulated and differentially expressed in MB} $\mathrm{G}$ protein-coupled receptor kinases (GRKs) initiate GPCR (CXCR4) desensitization by recruiting the binding of $\beta$-arrestins to the complex and regulate CXCR4 signaling by mediating the phosphorylation and subsequent internalization of the agonist-occupied receptor [8]. Since we demonstrated that PDGFR activation is required for CXCL12-mediated CXCR4 signaling, we questioned whether PDGFR signaling functions to suppress specific GRK expression and/or activity that would normally act to inhibit CXCR4. To identify the best candidate GRK to test, we first interrogated our microarray dataset of $29 \mathrm{MB}$ and found that GRK1 and 7 are not expressed by $\mathrm{MB}$; however, among the structurally related GRK4 group consisting of GRK4, 5 and 6, GRK6 was observed to have the lowest relative expression $(\mathrm{P}<0.01$, Figure $1 \mathrm{~B}$ and Table 2). Since our current $\mathrm{MB}$ database has too few metastatic MB to make correlations with progression, we re-investigated our previously published MB microarray database of 9 metastatic and 14 non-metastatic $\mathrm{MB}[5]$ and found that the percentage of tumors with detectable GRK6 expression is distinctly lower in those patients with metastatic MB (22\%), compared to those with non-metastatic MB (43\%), while by comparison, the percentage of tumors with detectable GRK5 mRNA does not appear different between these groups, suggesting that GRK6 may be differentially regulated in metastatic MB (Figure 1C). However, because of the small sample size only a trend rather than statistical significance could be observed. GRK4 was not analyzed in our previous data set. GRK6 expression is not significantly different between $\mathrm{SHH}$ and non-SHH MB, or between histology type, or those alive or deceased in the $\mathrm{SHH}$ 
Table 2 mRNA profiles of GRKs and PDGFR/PDGF in SHH vs. Non-SHH MB

\begin{tabular}{|c|c|c|c|c|c|c|c|}
\hline \multicolumn{8}{|l|}{ SHH MB } \\
\hline Pathological diagnosis & Patient status & GRK4 & GRK5 & GRK6 & PDGFRA & PDGFD & PDGFA \\
\hline Desmoplastic & DECEASED & 122 & 215 & 65 & 941 & 300 & 666 \\
\hline Desmoplastic & ALIVE & 140 & 154 & 56 & 1071 & 392 & 236 \\
\hline Desmoplastic & ALIVE & 80 & 77 & 60 & 911 & 417 & 192 \\
\hline Anaplastic & DECEASED & 49 & 355 & 117 & 48 & 454 & 226 \\
\hline Classic & ALIVE & 108 & 78 & 82 & 723 & 65 & 237 \\
\hline Classic & DECEASED & 118 & 184 & 86 & 469 & 139 & 391 \\
\hline Classic & DECEASED & 134 & 235 & 59 & 2166 & 231 & 114 \\
\hline Classic & DECEASED & 162 & 1253 & 75 & 926 & 98 & 471 \\
\hline Classic & ALIVE & 60 & 265 & 84 & 405 & 80 & 87 \\
\hline Classic & ALIVE & 72 & 148 & 93 & 773 & 310 & 91 \\
\hline \multirow[t]{2}{*}{ Classic, M+ } & DECEASED & 101 & 343 & 71 & 767 & 122 & 182 \\
\hline & Mean \pm SD & $104 \pm 36$ & $301 \pm 329$ & $77 \pm 18$ & $836 \pm 530$ & $237 \pm 145$ & $263 \pm 179$ \\
\hline \multicolumn{8}{|l|}{ Non-SHH MB } \\
\hline MBEN & ALIVE & 171 & 245 & 72 & 73 & 155 & 67 \\
\hline Anaplastic & ALIVE & 251 & 344 & 69 & 58 & 116 & 102 \\
\hline Anaplastic & ALIVE & 272 & 186 & 110 & 21 & 63 & 84 \\
\hline Classic & ALIVE & 142 & 624 & 74 & 190 & 10 & 32 \\
\hline Classic & ALIVE & 186 & 253 & 76 & 322 & 63 & 111 \\
\hline Classic & ALIVE & 192 & 235 & 64 & 406 & 49 & 36 \\
\hline Classic & ALIVE & 144 & 666 & 58 & 187 & 52 & 41 \\
\hline Classic & ALIVE & 139 & 217 & 71 & 25 & 67 & 125 \\
\hline Classic & ALIVE & 143 & 217 & 58 & 43 & 78 & 40 \\
\hline Classic & DECEASED & 141 & 293 & 29 & 388 & 100 & 64 \\
\hline Classic & DECEASED & 150 & 278 & 51 & 102 & 29 & 16 \\
\hline Classic & ALIVE & 252 & 370 & 120 & 145 & 23 & 31 \\
\hline Classic, M+ & DECEASED & 142 & 454 & 69 & 727 & 79 & 172 \\
\hline Classic & ALIVE & 242 & 173 & 70 & 57 & 245 & 35 \\
\hline Classic & ALIVE & 207 & 435 & 70 & 49 & 54 & 44 \\
\hline Classic & ALIVE & 220 & 731 & 81 & 191 & 58 & 41 \\
\hline Classic & ALIVE & 239 & 142 & 42 & 61 & 92 & 84 \\
\hline \multirow[t]{3}{*}{ Classic } & ALIVE & 285 & 615 & 88 & 7 & 68 & 69 \\
\hline & Mean \pm SD & $195 \pm 51$ & $360 \pm 186$ & $71 \pm 21$ & $170 \pm 186$ & $78 \pm 54$ & $66 \pm 40$ \\
\hline & SHH:non-SHH MB & & & & $+5 \mathrm{X}$ & $+3 X$ & $+4 X$ \\
\hline \multicolumn{8}{|c|}{ SHH desmoplastic vs. desmoplastic MB } \\
\hline Desmoplastic & DECEASED & 122 & 215 & 65 & 941 & 300 & 666 \\
\hline Desmoplastic & ALIVE & 140 & 154 & 56 & 1071 & 65 & 237 \\
\hline \multirow[t]{2}{*}{ Desmoplastic } & ALIVE & 80 & 77 & 60 & 911 & 122 & 182 \\
\hline & Mean \pm SD & $114 \pm 31$ & $149 \pm 69$ & $60 \pm 5$ & $974 \pm 85$ & $162 \pm 123$ & $362 \pm 265$ \\
\hline Anaplastic & DECEASED & 49 & 355 & 117 & 48 & 392 & 236 \\
\hline Classic & ALIVE & 108 & 78 & 82 & 723 & 417 & 192 \\
\hline Classic & DECEASED & 118 & 184 & 86 & 469 & 454 & 226 \\
\hline Classic & DECEASED & 134 & 235 & 59 & 2166 & 139 & 391 \\
\hline Classic & DECEASED & 162 & 1253 & 75 & 926 & 231 & 114 \\
\hline
\end{tabular}


Table 2 mRNA profiles of GRKs and PDGFR/PDGF in SHH vs. Non-SHH MB (Continued)

\begin{tabular}{|c|c|c|c|c|c|c|c|}
\hline Classic & ALIVE & 60 & 265 & 84 & 405 & 98 & 471 \\
\hline Classic & ALIVE & 72 & 148 & 93 & 773 & 80 & 87 \\
\hline \multirow[t]{2}{*}{ Classic, M+ } & DECEASED & 101 & 343 & 71 & 767 & 310 & 91 \\
\hline & Mean \pm SD & $101 \pm 38$ & $358 \pm 374$ & $83 \pm 17$ & $785 \pm 623$ & $265 \pm 149$ & $226 \pm 141$ \\
\hline
\end{tabular}

SHH MB, sonic-hedgehog medulloblastoma; MBEN, medulloblastoma with extensive nodularity; $\mathrm{M+}$, metastatic.

tumor group. We thus focused on GRK6 in subsequent studies as a candidate GRK that could be involved in GF/ PDGFR-mediated regulation of CXCR4 signaling.

GRK6 expression is negatively regulated by GF receptor/ PDGFR at the transcriptional and post-translational level Since we were unable to detect GRK6 protein by IHC in $\mathrm{MB}$ (negative staining, compared to positive control in other tissues, data not shown), we investigated MB cells to determine whether GRK6 expression can be induced, and if so, whether expression is dependent on GF receptor/PDGFR. To address this question, we utilized previously generated $\mathrm{MB}$ cells with stable knock-down of PDGFR [6], and then investigated the level of GRK6 mRNA expression by quantitative real-time RT-PCR. As shown in Figure 2A, GRK6 mRNA level was significantly higher in the cells with down-regulation of PDGFR (1.5-fold increase in D556 B9 and Daoy A4
PDGFR knock-down cells, compared to the control cells $\mathrm{NC1}$; $\mathrm{P}<0.05$ ), indicating that GRK6 mRNA expression is normally suppressed by PDGFR. To confirm that PDGFR signaling regulates GRK6 protein expression, we used Western blot to evaluate the level of GRK6 in the PDGFR knock-down cells. As shown in Figure 2B, the GRK6 protein level was markedly increased with or without CXCL12 treatment $(15 \mathrm{~min})$ in the PDGFR knock-down cells. Although PDGFR is reported to play a role in medulloblastoma, other GF receptors are involved in $\mathrm{MB}$ progression. We thus examined whether generalized GF signaling is involved in the regulation of GRK6 expression. Consistently, inhibition of GF receptor activation by GF withdrawal (starvation) similarly increased GRK6 protein levels in MB cells, which could be reversed back to undetectable levels by GF add-back over 48-72 $\mathrm{h}$ (Figure 2C, left and middle panels). This indicates that under normal growth conditions, $\mathrm{MB}$
A

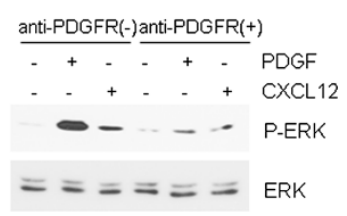

B

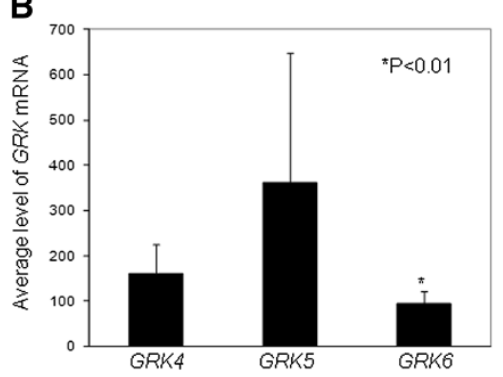

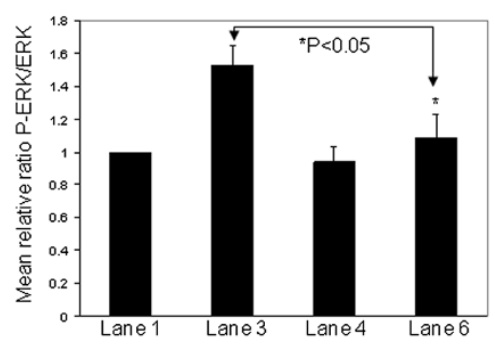

C

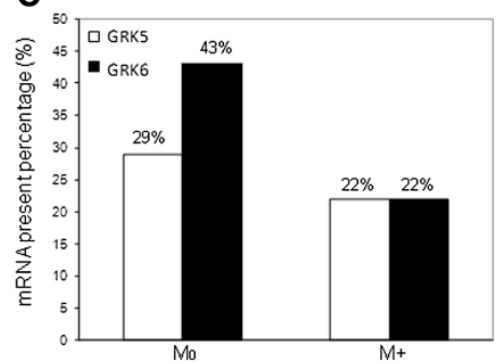

Figure 1 PDGFR activity is required for optimal CXCR4 signaling in SHH MB cells and GRK6 is downregulated and differentially expressed in MB. (A) Left panel: Daoy cells were starved and treated with or without $1 \mu \mathrm{g} / \mathrm{ml}$ anti-PDGFR $\beta$ blocking antibody for $24 \mathrm{~h}$, then stimulated by $10 \mathrm{ng} / \mathrm{ml}$ PDGF-BB or $100 \mathrm{ng} / \mathrm{ml}$ CXCL12 (SDF-1a) for $15 \mathrm{~min}$. Western blot of P-ERK shows PDGFR function is required for optimal CXCR4 signaling; Right panel: Quantitative analysis of Western blot shows CXCL12-induced P-ERK is significantly decreased by PDGFR $\beta$ blocking antibody ( $P<0.05$, lane 3, $1.53 \pm 0.12$ vs. lane 6, 1.09 0.15, three independent experiments). (B) 29 human MB specimens were collected and used for microarray analysis. Average expression level of GRK6 mRNA is lowest among the detectable GRKs, (P<0.01). (C) Microarray database of 9 human metastatic and 14 non-metastatic MB showed that the percentage of tumors with detectable GRK6 mRNA was notably decreased in metastatic $M B(M+, 22 \%)$, compared to non-metastatic $M B\left(M_{0}, 43 \%\right)$. However, the percentage of tumors with detectable GRK5 mRNA was not appreciably different in $M+(22 \%)$, vs. $M_{0}(29 \%)$. 


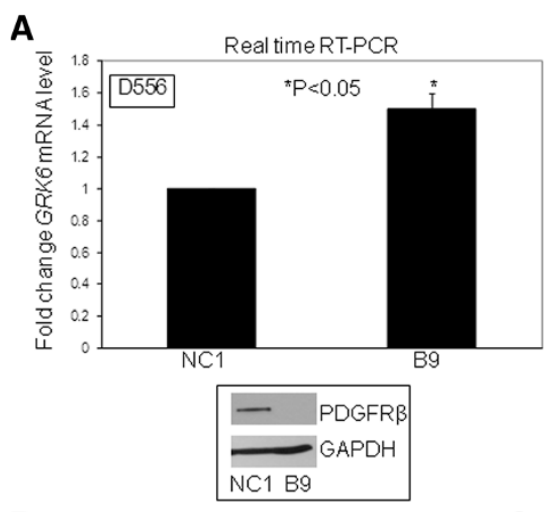

B
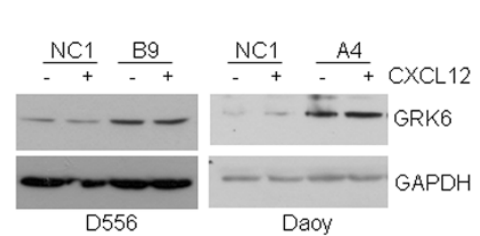

C

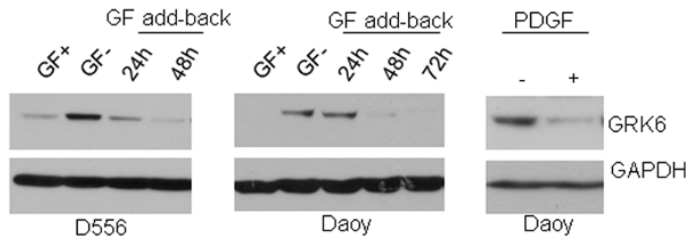

Figure 2 GRK6 expression is negatively regulated by GF/PDGFR. (A) Quantitative real time RT-PCR was performed to determine the expression of GRK6 mRNA in medulloblastoma cells with normal vs. downregulated PDGFR expression. (A) GRK6 mRNA is increased 1.5 folds in B9 (PDGFR $\beta$ down-regulated by shRNA in D556, shown below left panel) and 1.5 folds in A4 (PDGFR $\beta$ down-regulated by shRNA in Daoy, shown below right panel) respectively, compared to the parental cells (D556 NC1 or Daoy NC1), $P<0.05(N=3)$. (B) Protein level of GRK6 is increased in D556 (B9) and Daoy (A4) with or without CXCL12 treatment. (C) D556 or Daoy was cultured in EMEM medium containing 10\% serum (GF+) or serum-free EMEM (GF-) for $24 \mathrm{~h}$, then added 10\% serum to the cells cultured in serum-free medium (GF add-back) and cells grown for 24-72 $\mathrm{h}$. Cell lysates were harvested for Western Blot. GF withdrawal results in robust increase of GRK6 in D556 and Daoy (left and middle panels). In right panel, Daoy cells were starved for $24 \mathrm{~h}$ and then treated with $10 \mathrm{ng} / \mathrm{ml}$ PDGF-BB for $24 \mathrm{~h}$. GRK6 level determined by Western blot shows marked decrease with PDGF treatment.

A
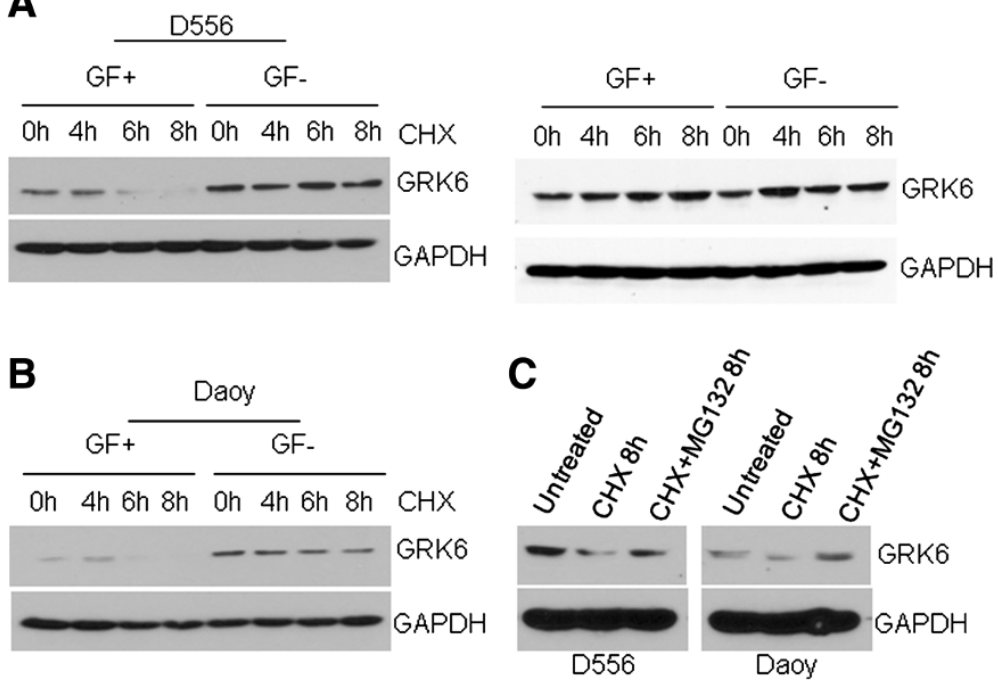

Figure 3 Growth factor treatment of medulloblastoma cells induces degradation of GRK6 via the proteasomal pathway. (A) D556 or (B) Daoy was cultured in EMEM medium with GF + or serum-free EMEM (GF-), treated with $100 \mu \mathrm{g} / \mathrm{ml}$ CHX or without CHX at indicated time points. GRK6 level was determined by Western blot. Growth factor withdrawal increases stability of GRK6 (C) Daoy or D556 was treated with CHX alone or CHX plus $10 \mu \mathrm{M} \mathrm{MG132}$ for $8 \mathrm{~h}$, then GRK6 protein level was examined by Western blot. GRK6 stability is maintained in the presence of proteasomal inhibitor MG132. 
GRK6 is suppressed to near undetectable levels. Furthermore, treatment of Daoy cells with PDGF alone for $24 \mathrm{~h}$ was sufficient to induce near ablation of GRK6 (Figure 2C, right panel). These data indicate that GRK6 expression is negatively regulated by GF receptor/ PDGFR.

Although PDGFR suppresses GRK6 mRNA expression, the marked changes in protein expression seemed to indicate that PDGFR induces additional post-translational regulation of GRK6. To examine whether GF activation altered the protein stability of GRK6, we treated MB cells with $100 \mu \mathrm{g} / \mathrm{ml}$ cycloheximide $(\mathrm{CHX})$ at the indicated time points under normal growth conditions or without GF (starved for $24 \mathrm{~h}$ prior to $\mathrm{CHX}$ treatment). Robust degradation of GRK6 to a near undetectable level was observed in cells growing in normal growth medium at $6 \mathrm{~h}$ after CHX treatment; however, GRK6 protein appeared to be relatively stable in the cells grown in the absence of GF at 6-8 h after CHX treatment (Figure 3A, left panel and 3B). No significant difference of GRK6 protein expression was observed between cells growing in normal growth medium and cells in medium without GF at the indicated time points when cells were not treated with $\mathrm{CHX}$ to inhibit protein synthesis (Figure 3A, right panel). Similarly, increased GRK6 stability was observed following CHX treatment in the PDGFR knock-down MB cells (not shown). To test whether GRK6 undergoes proteasomal pathway degradation, we treated the cells with and without the proteasome inhibitor, MG132, prior to $\mathrm{CHX}$ treatment. As shown in Figure 3C, proteasomal inhibition prevented GRK6 degradation. These data indicate that GRK6 protein stability is negatively regulated under normal growth conditions by GFs, including PDGFR, at the post-translational level through proteasomal degradation.

\section{GRK6 expression is negatively regulated in a Src-dependent manner}

Src is an important downstream effector of GF receptor/PDGFR signaling and plays a critical role in tumorigenesis [28]. To determine whether Src is involved in the regulation of GRK 6 expression at the transcriptional level, we performed real-time RT-PCR of GRK6 mRNA in $\mathrm{MB}$ cells transfected with control or Src siRNA. As shown in Figure 4A, down-regulation of Src results in a significant increase of GRK6 mRNA (1.5-fold increase in D556 $48 \mathrm{~h}$ after transfection, 3-fold increase in Daoy $96 \mathrm{~h}$ after transfection). At the protein level by Western blot (Figure 4B), Src downregulation resulted in increased GRK6 levels (48 h in D556 or 96 h in Daoy after transfection). To confirm Src's role in regulating GRK6 expression, we generated stable MB cells for Doxycycline (Dox)-inducible overexpression of Src. Treatment of stable MB cells with $500 \mathrm{ng} / \mathrm{ml}$ Dox for $48 \mathrm{~h}$ showed
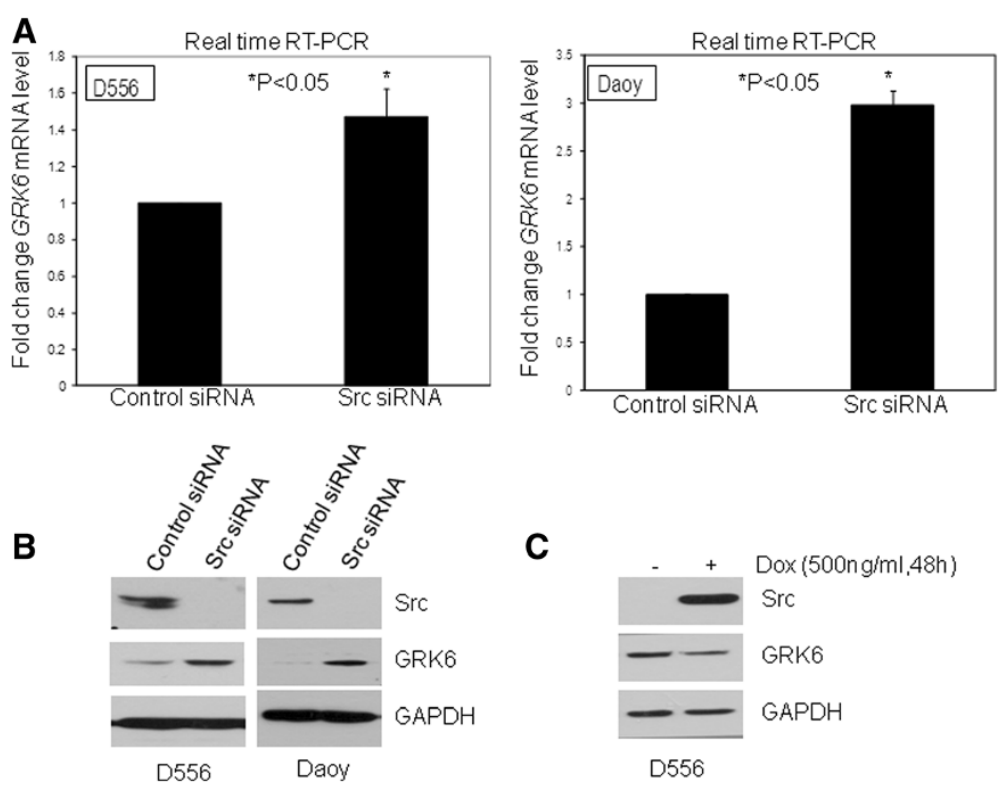

Figure 4 GRK6 expression is negatively regulated in a Src-dependent manner. MB cells were transfected with control siRNA or Src siRNA, and then the cells were harvested at $48 \mathrm{~h}$ (D556) or $96 \mathrm{~h}$ (Daoy) after transfection and examined by real time RT-PCR or Western Blot. (A) Real time RT-PCR shows expression of GRK6 mRNA is significantly increased 1.5 folds in D556 and 3 folds in Daoy by Src siRNA transfection, P<0.05, respectively. Shown is the representative of three experiments. (B) Western blot shows that the protein level of GRK6 is increased by Src siRNA. (C) Retro-X Tet on Src-inducible stable cell line was treated by $500 \mathrm{ng} / \mathrm{ml}$ Dox for $48 \mathrm{~h}$, and then, Src and GRK6 expression were examined by Western blot. Src- induced expression results in decreased GRK6 protein level. 
that Src overexpression resulted in decreased GRK6, compared to the same cells without Dox treatment (Figure 4C). Dox treatment had no effect on Src or GRK6 expression in non-transfected parental cells (not shown). Using the Src inhibitor, dasatinib, our data indicate that pharmacologic Src blockade can also induce GRK6 expression (not shown). These data demonstrate that Src, a major downsteam effector of PDGFR and other GF-activated pathways, is sufficient to mediate negative regulation of GRK6 expression.

\section{CXCR4 signaling and MB cell migration is inhibited by GRK6}

To test the function of GRK6 in MB cells, we first used specific GRK6 siRNA to down-regulate GRK6 expression in MB cells and examined the impact of altered GRK6 expression on CXCL12/CXCR4 signaling and cell migration. As shown in Figure 5A, GRK6 down-regulation enhanced CXCL12-mediated phosphorylation of ERK (P-ERK) compared to cells transfected with control siRNA, indicating that GRK6 normally acts to suppress CXCR4 signaling in MB cells. Expression of GRK5, which shares a sequence similar to GRK6, was not affected by GRK6 siRNA transfection. We subsequently demonstrated using Boyden chamber migration assays that serummediated cell migration was significantly enhanced in the GRK6 down-regulated MB cells (Figure 5B). Consistent with these results, we found that Src overexpression, which we showed reduces GRK6 expression, similarly promotes cell migration in a scratch assay (data not shown).

To confirm the role of GRK6 in MB cells, we used lentiviral FUW-mCherry (control) and FUW-C-GRK6 to generate stable $\mathrm{MB}$ cells overexpressing GRK6. As shown in Figure 6A, CXCL12-mediated P-ERK was decreased in cells with GRK6 overexpression, compared to control cells. Furthermore, treatment of cells with
AMD3100, an antagonist of CXCR4, at $2.5 \mu \mathrm{g} / \mathrm{ml}$ completely abolished CXCL12-induced P-ERK in FUWGRK6, but not in FUW-Cherry cells (Figure 6A, right panel) $[\mathrm{P}<0.05$, lane $3,0.59 \pm 0.1$ vs. lane $6,0.31 \pm 0.03$ by comparing the densitometry of CXCL12-induced PERK/ERK in Daoy cells with or without overexpression of GRK6. The ratio of P-ERK/ERK in lane 1 is equal to 1.00 (100\%)], indicating that GRK6 overexpression potentiates the effect of AMD3100. In Boyden chamber migration assays, we found that $\mathrm{MB}$ cell migration was significantly inhibited by overexpression of GRK6 (Figure 6B). Similar results were observed in scratch assays (data not shown). To further validate the role of GRK6 in MB cells, we conducted cell migration and proliferation assays using xCELLigence [29], which allows for monitoring cell activity in real-time. As shown in Figure 6C (left panel), migration in serum-free conditions is similar between FUW-Cherry and FUW-GRK6 cells; however, in the presence of serum, migration is significantly decreased in FUW-GRK6 cells compared to control FUW-Cherry cells. At approximately $16.5 \mathrm{~h}$, the average cell index (number of migratory cells) in FUW-Cherry is 1.7-fold higher than in FUW-GRK6 cells $(\mathrm{P}<0.01)$. To assess whether the difference in migration was the result of differences in cell viability and proliferation, we simultaneously performed a proliferation assay at the beginning of the migration assay. The results showed no significant difference in the proliferative capacity of the control and GRK6 overexpressing cells at either high $\left(2 \times 10^{4} /\right.$ well $)$ or low $\left(5 \times 10^{3} /\right.$ well $)$ cell density (Figure $6 \mathrm{C}$, right panel). Together, these data indicate that in these MB cells GRK6 functions to suppress CXCR4 signaling and inhibit cell migration, and thus optimal signaling and migration is maintained through ongoing suppression of GRK6 levels and activity.
A

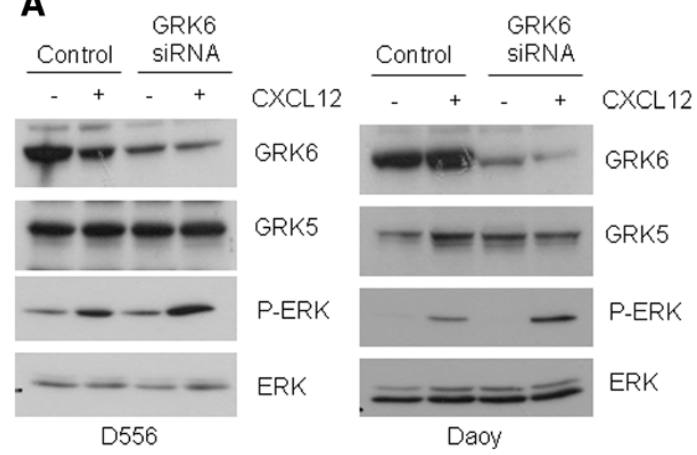

B

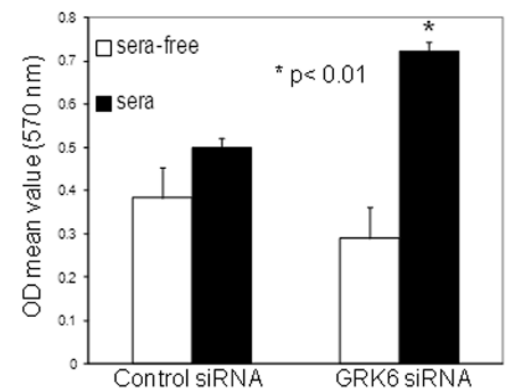

Figure 5 CXCR4 signaling and MB cell migration is inhibited by GRK6. (A) D556 or Daoy was transfected with control siRNA or GRK6 siRNA. The cells were starved for $24 \mathrm{~h}$ after transfection and then stimulated by $100 \mathrm{ng} / \mathrm{ml}$ CXCL12 (SDF-1a) for $15 \mathrm{~min}$. The results show that downregulation of GRK6 causes increased CXCL12-induced P-ERK in both cell lines. (B) Daoy was transfected with control siRNA or GRK6 siRNA and then starved for $24 \mathrm{~h}$ prior to examination by Boyden chamber migration assay. Results show serum-mediated migration is significantly increased in the cells transfected with GRK6 siRNA $(P<0.01)$. 


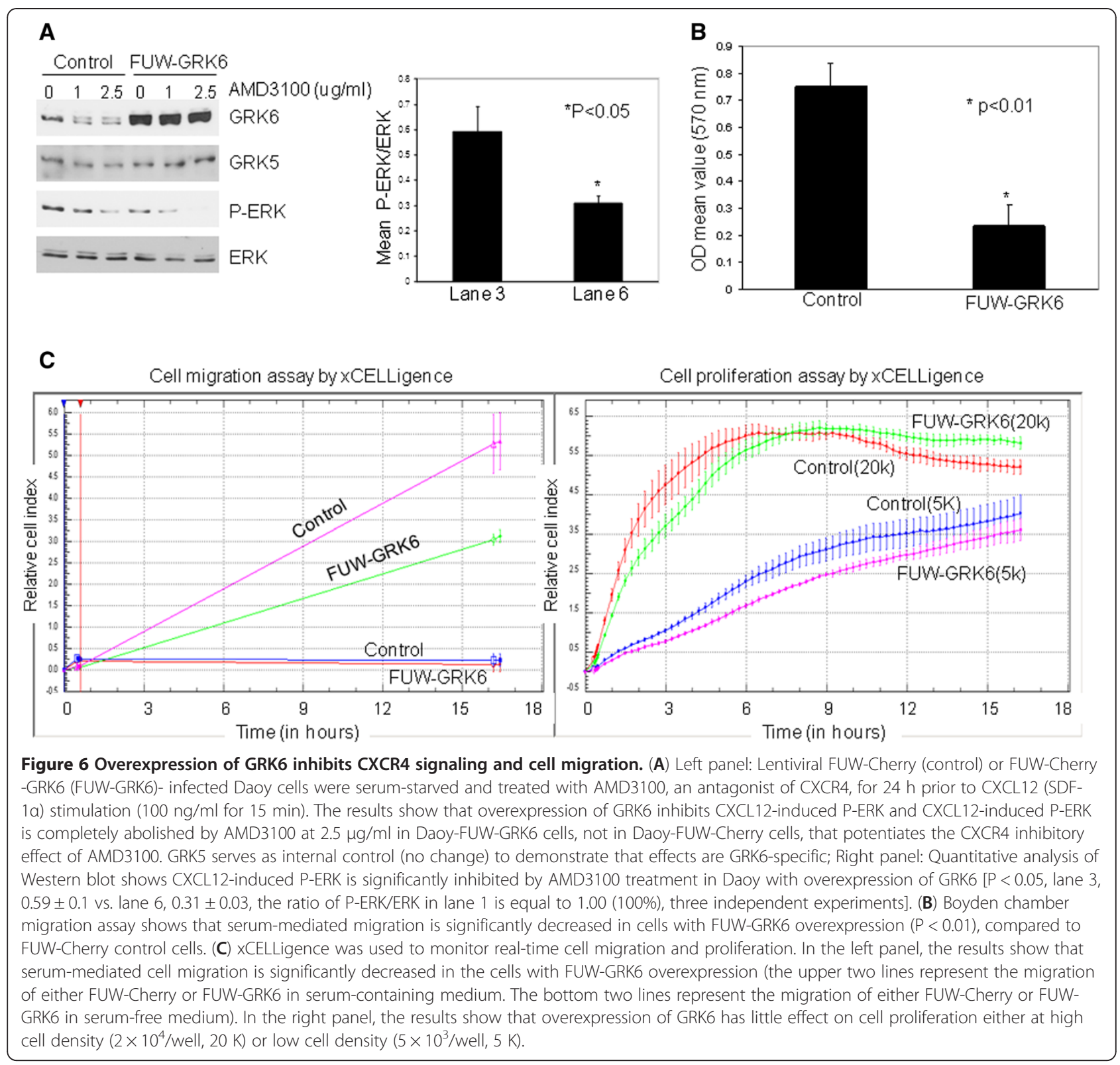

\section{Discussion}

Children diagnosed with sonic hedgehog-activated MB ( $\mathrm{SHH} \mathrm{MB}$ ) displaying desmoplastic histology have a good prognosis, while those with non-desmoplastic histology have higher rates of metastasis and an intermediate prognosis, indicating that additional factors to $\mathrm{SHH}$ activation account for the clinical dichotomy observed [2-4,17]. Recent evidence shows that CXCR4 signaling, which is critical to the proliferation and migration of granule neuron precursors during development, is dependent on $\mathrm{SHH}$ for its activation in MB [13,18,30,31]. This finding, coupled to CXCR4's reported role in tumor progression [14,16,32,33], point towards dysregulated CXCR4 signaling as a possible key determinant of $\mathrm{SHH} \mathrm{MB}$ clinical behavior. We observe high co-expression levels of CXCR4 and CXCL12, as well as PDGFRA, distinctly associated with $\mathrm{SHH}$ MB. Herein, we demonstrate that GF receptor/PDGFR and Src, a major GF/PDGFR downstream effector, act to suppress the expression and stability of the $G$ protein-coupled receptor kinase GRK6 in MB cells, which in turn functions to maintain CXCR4 signaling and promote cell migration, thereby identifying a new mechanism for the dysregulation of this signaling axis in MB. This finding has important implications for our understanding of $\mathrm{SHH} \mathrm{MB}$ clinical behavior and potential translation to therapeutic targeting. 
GPCRs are desensitized by agonist-induced GRKmediated phosphorylation, whereby the receptors are uncoupled from heterotrimeric G-protein signaling. Suppression of GRKs, and loss of GRK-mediated desensitization, can result in the prolonged activation of GPCRs. The involvement of CXCR4 in cancer metastasis appears to be due to dysregulation of the receptor leading to enhanced CXCR4 signaling [14,24]. In breast cancer cells, a similar functional relationship between the PDGFR pathway and CXCR4 has been reported, whereby overexpression of PDGF-D, which specifically binds to and activates PDGFRB, was shown to induce CXCR4 expression and promote lymph node metastasis [34]. GRKs can also regulate EGFR and PDGFR activity, and in turn, GRKs may be regulated at the mRNA and protein level by altered oncogenic receptor signaling [35].

The description of GRK6 expression and its functional role in cancer is very limited, and until now, has not been reported in MB. In this study, we found that the percentage of GRK6 expression is lower in MB tumors with metastasis (22\%), compared to those without metastasis (43\%); however, these data revealed only a trend in $\mathrm{MB}$, with the difference not being statistically significant due to the small sample size. GRK6 typically has a negative regulatory role in CXCR4 activation and CXCL12-induced cell migration [24,26]. For example, GRK6 deficiency is associated with impaired desensitization and enhanced CXCR4-mediated neutrophil migration and has been implicated in the pro-inflammatory response seen in rheumatoid arthritis [26,36]. However, in HeLa cells, siRNA-based functional screening identified GRK6 as a critical positive regulator of integrin-mediated cell adhesion and migration [37]. Similarly, GRK6 silencing in myeloma cells induced a tumor suppressor effect by inhibiting STAT3 phosphorylation and decreasing tumor cell survival [38].

To date, we have little knowledge regarding the regulation of GRK6. Herein, we demonstrate that GF/PDGFRSrc activation results in decreased expression of GRK6 at the transcriptional and post-translational level to maintain optimal CXCR4 signaling. In fact, we found that Src, a key mediator of PDGFR signaling and other GF-induced pathways [28], can independently regulate GRK6 expression, indicating that Src could be a critical therapeutic target in $\mathrm{MB}$, especially given its additional role as a central node in other pro-migratory and pro-survival signals. This therapeutic potential is further illustrated in our study, which shows that targeting CXCR4 with the inhibitor AMD3100, can be potentiated by the overexpression of GRK6. Since we show that Src suppresses GRK6, Src inhibitors could potentially be used to elevate levels of suppressive GRK6. Given that we have previously shown that PDGFR can regulate Rac1-Pak1 signaling important for cytoskeletal rearrangements required for $\mathrm{MB}$ cell migration [6], it remains to be seen whether the combined inhibition of PDGFR-Src-CXCR4 may act synergistically to suppress $\mathrm{SHH} \mathrm{MB}$ growth and progression. In our study, the observation that specific alteration of GRK6 did not itself impact MB cell growth indicates that GRK6 is a critical mediator of GF receptor/PDGFR-Src oncogenic signaling for CXCR4-mediated migration, but is not essential for maintaining CXCR4-mediated growth. Rather, other mechanisms, and perhaps other GRKs may be necessary to regulate growth. Although we focused on GRK6 in this study because of its apparent dysregulated expression in metastatic $\mathrm{MB}$, it is possible that other GRKs that we found expressed by MB (i.e. GRK4 and 5) may also play a role in $\mathrm{MB}$ growth and progression. For example, PDGFR/Src has been shown to regulate GRK2 activity in other cell types and the suppression of GRK3 appears necessary for maximal glioblastoma cell growth [35,39]. Further studies will be necessary to investigate the potential functional role and regulation of GRK4 and GRK5 in MB as well as the effect of targeting GRKs and PDGFR-Src dysregulation of the CXCR4 signaling axis on $\mathrm{MB}$ progression in vivo.

\section{Conclusion}

In summary, we found that GF receptor/PDGFR-Srcmediated suppression of GRK6 acts to promote CXCR4 signaling and cell migration irrespective of CXCL12 ligand and demonstrate a novel mechanism of GF receptor/ PDGFR-Src-mediated dysregulation of CXCR4 signaling that promotes $\mathrm{MB}$ cell migration, and thus targeting this axis in $\mathrm{SHH} \mathrm{MB}$ could represent a potent new therapeutic strategy for $\mathrm{MB}$.

\section{Methods}

\section{Cell culture and reagents}

Daoy and D556 human medulloblastoma cells were cultured in EMEM with 10\% fetal bovine serum (FBS). CXCL12 and anti-human PDGFR $\beta$ antibody (blocking antibody, cat\# AF385) were purchased from R \& D Systems (Minneapolis, MN).

\section{Patient samples}

MB frozen tumor specimens were consented for and obtained from the Children's Healthcare of Atlanta (CHOA) $(n=29)$ tumor tissue repository. The research protocols and amendments were approved by the institutional review boards of $\mathrm{CHOA}$, Emory University, and the CHOA tumor bank committee. All tumor specimens were studied as deidentified tissue samples and reviewed as part of this study by board certified neuropathologist (MS) according to WHO criteria (2007). 


\section{Expression profiling}

RNA was extracted from 29 frozen MB tumor samples using the Trizol reagent (Invitrogen, Carlsbad, CA) and was profiled by AROS Biosciences on the Affymetrix human genome U133 Plus 2.0 array with the $3^{\prime}$ IVT Express Labeling Kit (Affymetrix, Santa Clara, CA). CEL files were preprocessed using RMA [40] and probesets collapsed to genes using the Genepattern software suite (http://www. broadinstitute.org/cancer/software/genepattern/). Sample were then assigned to a molecular subgroups as previously described, using a classifier based on support-vector machines [17]. In addition, the database from previously published microarray expression profiling of medulloblastoma [5] was used to supplement mRNA profiling data analysis of metastatic vs. non-metastatic medulloblastoma. The relative mean expression level listed for each gene is calculated by the Affymetrix software.

\section{Western blot}

Western blot of whole cell lysates harvested in lysis buffer (Cell Signaling Technology, Danvers, MA) was performed with the following primary antibodies: GRK5, GRK6 and PDGFR $\beta$ (Santa Cruz, CA); phospho-PDGFR $\beta$ (Tyr751), phospho-ERK and ERK1/2 (Cell Signaling Technology). Goat anti-mouse or rabbit horseradish peroxidase secondary antibodies (Santa Cruz) were used and the immunoreactive bands were detected by ECL. Densitometric analysis of the visualized bands was used to quantitate and compare the relative changes in levels of target proteins.

\section{Real time RT-PCR}

Total RNA was prepared from human MB cell lines (Daoy or D556). Random-primed single-stranded cDNA was made from total RNA by using the Superscript III kit (Cat\# 18080-051, Invitrogen, Carlsbad, CA). The following oligonucleotides as primers were used for real time PCR: Glyceraldehyde-3-phosphate dehydrogenase (GAPDH), 5' - CG T G CCGCCTGGAGAAACC-3' (forward), 5' TGGA A GAGTGGGAGTTGCTGTTG-3' (reverse). Human GRK6 primers were purchased from Qiagen (cat\# QT00043295). GRK6 cDNA was amplified by real-time PCR $\left(35\right.$ cycles: $95^{\circ} \mathrm{C}$ for $10 \mathrm{~min}, 94^{\circ} \mathrm{C}$ for $1 \mathrm{~min}, 55^{\circ} \mathrm{C}$ for $1 \mathrm{~min}, 72^{\circ} \mathrm{C}$ for $1 \mathrm{~min}$, extension $72^{\circ} \mathrm{C}$ for $8 \mathrm{~min}$ ) in real-time cycler from Applied Biosystems (Foster City, CA). Each sample was set at least in triplicate for each PCR. Data analysis was performed according to the absolute standard curve method. Data are presented in relation to the respective housekeeping gene and normalized the fold change of control cells to 1 , then calculated the relative fold changes.

\section{SiRNA and shRNA transfection}

Human GRK6 ON-TARGETplus SMARTpool siRNA (L-004627-00-0005), Src ON-TARGETplus SMARTpool
siRNA (L-003175-00-0005) and negative control nontargeting siRNA (D-001810-01-05) were purchased from Dharmacon (Chicago, IL). Each SMARTpool is a mixture of 4 siRNA sequences with advantages in both efficacy and specificity. For siRNA transfections, $1.5 \times 10^{5}$ cells were seeded in each well of a six-well plate and grown to $50-60 \%$ confluency prior to transfection. Cells were transfected with siRNA using Lipofectamine 2000 (Invitrogen, Carisbad, CA) for 48-96 h according to the manufacturer's instruction and then cells were treated and harvested for further experiments. The stable shPDGFR and control shRNA cells (Daoy and D556) used in these experiments were previously generated by us as described [6].

\section{GRK overexpressing cells}

The lentiviral FUW-mCherry and FUW-C-GRK6 were kindly provided by Dr. Joshua Rubin (Washington University in St Louis, MO). To make stable medulloblastoma cell lines with overexpression of GRK6, $4 \times 10^{5}$ cells were seeded in $60 \mathrm{~mm}$ dishes before infection and then, lentiviral FUW-mCherry and FUW-C-GRK6 were added into each dish for $6 \mathrm{~h}$. Media was changed and cells grown for 2 or 3 days before cell-sorting per the flow cytometry core facility protocols to separate sort-positive and sortnegative cells. Western Blots were performed at least three times to verify the stable cells.

\section{Src overexpressing inducible cells}

The plasmid pRetro HA-Src A was kindly provided by Dr. Hui Kuo Shu (Emory University, Atlanta, GA). Briefly, pCSrc A HA14 plasmid was first digested with Xho1, filled in with $\mathrm{T} 4$ polymerase and finally digested with BamH1. The excised HA-Src A cDNA was inserted into the cloning sites between BamH1 and Nru1 of pRetroXTight-Pur (Clontech, Mountain View, CA, USA). The regulatory vector and the pRetro HA-Src A were transfected into phoenix-ampho package cells and then the supernatant was harvested to infect MB cell lines. The cells were selected by G418 plus puromycin after infection. $500 \mathrm{ng} / \mathrm{ml}$ doxycycline (Dox) was added to induce expression of Src. The overexpression of Src was identified by Western Blot.

\section{Boyden chamber migration assay}

Fibronectin-mediated cell adhesion and migration was assessed using the QCM-FN Quantitative Cell Migration Assay (cat\# ECM580, Millipore). Briefly, cells were cultured to $80 \%$ confluency and harvested with trypsin/ EDTA and resuspended in serum-free EMEM. $1.0 \times 10^{5}$ cells in $200 \mu \mathrm{L}$ serum-free EMEM were seeded into the pre-coated (fibronectin or BSA) upper chambers. The lower well contained $500 \mu \mathrm{L}$ EMEM with 10\% FBS. Each chamber was set in triplicate. The cells were incubated for 
4-5 h at $37^{\circ} \mathrm{C}$, stained with cell staining solution and then washed in distilled water. Cells were eluted with extraction solution and $100 \mu \mathrm{L}$ transfered to a 96-well microtiter plate for absorbance reading $(570 \mathrm{~nm})$.

\section{xCELLigence migration and proliferation assays}

$x C E L L i g e n c e$ instrumentation and protocols for the measurement of real-time migration and proliferation were provided by Roche Diagnostics Corporation. xCELLigence is an electrical impedance-based system that allows for the measurement of real-time cell migration and proliferation [29]. We used CIM plate (Cat\# 05665817001, Roche) for migration assay and the E-plate (Cat\# 05469830001, Roche) for proliferation assay. Briefly, for migration assay, we seeded $4 \times 10^{4}$ cells into each chamber and set 4 chambers for each cell type. After all chambers were set up, the CIM plate was put into xCELLigence instrument at $37^{\circ} \mathrm{C}$, $5 \% \mathrm{CO} 2$ incubator for migration assay. Similarly, we seeded $2 \times 10^{4}$ cells or $5 \times 10^{3}$ cells into each well and set up 4 wells for each cell type, then ran proliferation assay in $\mathrm{xCELLigence} \mathrm{instrument} \mathrm{at} 37^{\circ} \mathrm{C}, 5 \% \mathrm{CO} 2$ incubator. The impedance was recorded in 15 min intervals.

\section{Statistical analysis}

Group differences and p-values were calculated using Student's $t$-test. Difference of group percentage was calculated using Fisher's exact test. P values $<0.05$ were considered as statistically significant.

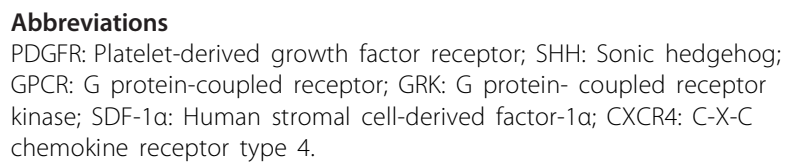

\section{Competing interests}

The authors declare that they have no competing interests.

\section{Authors' contributions}

LY participated in the design of the study, generated stable cell lines overexpressing GRKs, conducted Western blots, siRNA transfections, proliferation and migration assays, performed statistical and data analysis, and drafted the manuscript. $\mathrm{HZ}$ generated stable cell lines overexpressing Src, conducted real time RT-PCR and corresponding Western blots. JL performed PCR primer design, real time RT-PCR and corresponding statistical analysis. JBR aided in study design, data analysis and interpretation, critical revision of the manuscript, and provided the GRK lentivirus. YJC performed the microarray gene expression analysis. HKS generated pRetro HA Src A plasmid in his laboratory and provided the plasmid and technical assistance for generation of stable cell lines. MS provided neuropathology interpretation for all tissue specimens. TJM conceived the research, directed all experiments and provided the oversight for all data analysis, results interpretation and the draft of the final manuscript. All the authors have read and approved the final manuscript.

\section{Acknowledgments}

This study is supported by NIH R01CA111835 (TJM), in part from CURE Foundation (TJM) and NIH R01CA118389 (JBR).

\section{Author details}

'Department of Pediatrics, Aflac Cancer and Blood Disorders Center, Emory University School of Medicine, 2015 Uppergate Drive NE, Atlanta, GA 30322,
USA. ${ }^{2}$ Department of Pediatrics, Anatomy and Neurobiology, Washington University School of Medicine, St Louis, MO, USA. ${ }^{3}$ Departments of Neurology and Neurological Sciences, Stanford University School of Medicine, Stanford, CA 94305, USA. ${ }^{4}$ Department of Radiation Oncology, Emory University School of Medicine, Atlanta, GA, USA. ${ }^{5}$ Department of Pathology, Emory University School of Medicine, Atlanta, GA 30322, USA.

Received: 1 October 2012 Accepted: 28 February 2013

Published: 5 March 2013

\section{References}

1. von Hoff K, Rutkowski S: Medulloblastoma. Curr Treat Options Neurol 2012, 14:416-426.

2. Ellison DW, Kocak M, Dalton J, Megahed H, Lusher ME, Ryan SL, Zhao W, Nicholson SL, Taylor RE, Bailey S, Clifford SC: Definition of disease-risk stratification groups in childhood medulloblastoma using combined clinical, pathologic, and molecular variables. J Clin Oncol 2011, 29:1400-1407.

3. Northcott PA, Korshunov A, Witt H, Hielscher T, Eberhart CG, Mack S, Bouffet E, Clifford SC, Hawkins CE, French P, Rutka JT, Pfister S, Taylor MD: Medulloblastoma comprises four distinct molecular variants. J Clin Oncol 2011, 29:1408-1414.

4. Taylor MD, Northcott PA, Korshunov A, Remke M, Cho YJ, Clifford SC, Eberhart CG, Parsons DW, Rutkowski S, Gajjar A, Ellison DW, Lichter P, Gilbertson RJ, Pomeroy SL, Kool M, Pfister SM: Molecular subgroups of medulloblastoma: the current consensus. Acta Neuropathol 2012, 123:465-472.

5. MacDonald TJ, Brown KM, LaFleur B, Peterson K, Lawlor C, Chen Y, Packer RJ, Cogen P, Stephan DA: Expression profiling of medulloblastoma: PDGFRA and the RAS/MAPK pathway as therapeutic targets for metastatic disease. Nat Genet 2001, 29:143-152.

6. Yuan L, Santi M, Rushing EJ, Cornelison R, Macdonald TJ: ERK activation of p21 activated kinase-1 (Pak1) is critical for medulloblastoma cell migration. Clin Exp Metastasis 2010, 7:481-491.

7. Wu X, Northcott PA, Dubuc A, Dupuy AJ, Shih DJ, Witt H, Croul S, Bouffet E, Fults DW, Eberhart CG, Garzia L, Van Meter T, Zagzag D, Jabado N, Schwartzentruber J, Majewski J, Scheetz TE, Pfister SM, Korshunov A, Li XN, Scherer SW, Cho YJ, Akagi K, MacDonald TJ, Koster J, McCabe MG, Sarver AL, Collins VP, Weiss WA, Largaespada DA, Collier LS, Taylor MD: Clonal selection drives genetic divergence of metastatic medulloblastoma. Nature 2012, 482:529-533.

8. Gether U, Kobilka BK: G protein-coupled receptors. II. Mechanism of agonist activation. J Biol Chem 1998, 273:17979-17982.

9. Gutkind JS: The pathways connecting G protein-coupled receptors to the nucleus through divergent mitogen-activated protein kinase cascades. J Biol Chem 1998, 273:1839-1842.

10. Janowski M, Lukomska B, Domanska-Janik K: Migratory capabilities of human umbilical cord blood-derived neural stem cells (HUCB-NSC) in vitro. Acta Neurobiol Exp (Wars) 2011, 71:24-35.

11. Dziembowska M, Tham TN, Lau P, Vitry S, Lazarini F, Dubois-Dalcq M: A role for CXCR4 signaling in survival and migration of neural and oligodendrocyte precursors. Glia 2005, 50:258-269.

12. Vilz TO, Moepps B, Engele J, Molly S, Littman DR, Schilling K: The SDF-1 /CXCR4 pathway and the development of the cerebellar system. Eur J Neurosci 2005, 22:1831-1839.

13. Zhu Y, Matsumoto T, Mikami S, Nagasawa T, Murakami F: SDF1/CXCR4 signalling regulates two distinct processes of precerebellar neuronal migration and its depletion leads to abnormal pontine nuclei formation. Development 2009, 136:1919-1928.

14. Müller A, Homey B, Soto H, Ge N, Catron D, Buchanan ME, McClanahan T, Murphy E, Yuan W, Wagner SN, Barrera JL, Mohar A, Verástegui E, Zlotnik A: Involvement of chemokine receptors in breast cancer metastasis. Nature 2001, 410:50-56.

15. Busillo JM, Armando S, Sengupta R, Meucci O, Bouvier M: Site-specific phosphorylation of CXCR4 is dynamically regulated by multiple kinases and results in differential modulation of CXCR4 signaling. I Biol Chem 2010, 285:7805-7817.

16. Teicher BA, Fricker SP: CXCL12 (SDF-1)/CXCR4 pathway in cancer. Clin Cancer Res 2010, 16:2927-2931.

17. Cho YJ, Tsherniak A, Tamayo P, Santagata S, Ligon A, Greulich H, Berhoukim R, Amani V, Goumnerova L, Eberhart CG, Lau CC, Olson JM, Gilbertson RJ, Gajjar A, 
Delattre O, Kool M, Ligon K, Meyerson M, Mesirov JP, Pomeroy SL: Integrative genomic analysis of medulloblastoma identifies a molecular subgroup that drives poor clinical outcome. J Clin Oncol 2011, 29:1424-1430.

18. Sengupta R, Dubuc A, Ward S, Yang L, Northcott P, Woerner BM, Kroll K, Luo J, Taylor MD, Wechsler-Reya RJ, Rubin JB: CXCR4 activation defines a new subgroup of Sonic Hedgehog driven medulloblastoma. Cancer Res 2012, 72:122-132.

19. Pitcher JA, Freedman NJ, Lefkowitz RJ: G protein-coupled receptor kinases. Annu Rev Biochem 1998, 67:653-692.

20. Gainetdinov RR, Premont RT, Bohn LM, Lefkowitz RJ, Caron MG: Desensitization of $\mathrm{G}$ protein-coupled receptors and neuronal functions. Annu Rev Neurosci 2004, 27:107-144.

21. Pierce KL, Lefkowitz RJ: Classical and new roles of beta-arrestins in the regulation of G-protein-coupled receptors. Nat Rev Neurosci 2001, 2:727-733.

22. Luttrell LM, Lefkowitz RJ: The role of beta-arrestins in the termination and transduction of G-protein-coupled receptor signals. J Cell Sci 2002, 115:455-465.

23. Métayé T, Gibelin H, Perdrisot R, Kraimps JL: Pathophysiological roles of Gprotein-coupled receptor kinases. Cell Signal 2005, 17:917-928.

24. McCormick PJ, Segarra M, Gasperini P, Gulino AV, Tosato G: Impaired recruitment of GRK6 and beta-Arrestin 2 causes delayed internalization and desensitization of a WHIM syndrome- associated CXCR4 mutant receptor. PLoS One 2009, 4:e8102.

25. Fong AM, Premont RT, Richardson RM, Yu YR, Lefkowitz RJ, Patel DD: Defective lymphocyte chemotaxis in beta-arrestin2- and GRK6-deficient mice. Proc Natl Acad Sci U S A 2002, 99:7478-7483.

26. Vroon A, Heijnen CJ, Raatgever R, Touw IP, Ploemacher RE, Premont RT, Kavelaars A: GRK6 deficiency is associated with enhanced CXCR4mediated neutrophil chemotaxis in vitro and impaired responsiveness to G-CSF in vivo. J Leukoc Biol 2004, 75:698-704.

27. Penela P, Ribas $C$, Mayor $F$ Jr: Mechanisms of regulation of the expression and function of G protein-coupled receptor kinases. Cell Signal 2003, 15:973-981.

28. Summy JM, Gallick GE: Src family kinases in tumor progression and metastasis. Cancer Metastasis Rev 2003, 22:337-358.

29. Ke N, Wang $X, X u X$, Abassi YA: The xCELLigence system for real-time and label-free monitoring of cell viability. Methods Mol Biol 2011, 740:33-43.

30. Klein RS, Rubin JB, Gibson HD, DeHaan EN, Alvarez-Hernandez X, Segal RA, Luster AD: SDF-1 alpha induces chemotaxis and enhances Sonic hedgehog-induced proliferation of cerebellar granule cells. Development 2001, 128:1971-1981.

31. Hagihara K, Zhang EE, Ke YH, Liu G, Liu JJ, Rao Y, Feng GS: Shp2 acts downstream of SDF-1alpha/CXCR4 in guiding granule cell migration during cerebellar development. Dev Biol 2009, 334:276-284.

32. Yang $L$, Jackson E, Woerner BM, Perry A, Piwnica-Worms D, Rubin JB: Blocking CXCR4-mediated cyclic AMP suppression inhibits brain tumor growth in vivo. Cancer Res 2007, 67:651-658.

33. Rubin JB, Kung AL, Klein RS, Chan JA, Sun Y, Schmidt K, Kieran MW, Luster $A D$, Segal RA: A small-molecule antagonist of CXCR4 inhibits intracranial growth of primary brain tumors. Proc Natl Acad Sci U S A 2003, 100:13513-13518.

34. Liu J, Liao S, Huang Y, Samuel R, Shi T, Naxerova K, Huang P, Kamoun W, Jain RK, Fukumura D, Xu L: PDGF-D improves drug delivery and efficacy via vascular normalization, but promotes lymphatic metastasis by activating CXCR4 in breast cancer. Clin Cancer Res 2011, 17:3638-3648.

35. Woerner BM, Luo J, Brown KR, Jackson E, Dahiya SM, Mischel P, Benovic JL, Piwnica-Worms D, Rubin JB: Suppression of G protein-coupled Receptor Kinase 3 expression is a feature of Classical GBM that is required for maximal growth. Mol Cancer Res 2012, 10:156-166.

36. Tarrant TK, Rampersad RR, Esserman D, Rothlein LR, Liu P, Premont RT, Lefkowitz RJ, Lee DM, Patel DD: Granulocyte chemotaxis and disease expression are differentially regulated by GRK subtype in an acute inflammatory arthritis model (K/BxN). Clin Immunol 2008, 129:115-122.

37. Chen Y, Lu B, Yang Q, Fearns C, Yates JR 3rd, Lee JD: Combined integrin phosphoproteomic analyses and small interfering RNA-based functional screening identify key regulators for cancer cell adhesion and migration. Cancer Res 2009, 69:3713-3720.

38. Tiedemann RE, Zhu YX, Schmidt J, Yin H, Shi CX, Que Q, Basu G, Azorsa D, Perkins LM, Braggio E, Fonseca R, Bergsagel PL, Mousses S, Stewart AK. Kinome-wide RNAi studies in human multiple myeloma identify vulnerable kinase targets, including a lymphoid-restricted kinase, GRK6. Blood 2010, 115:1594-1604.

39. Wu JH, Goswami R, Kim LK, Miller WE, Peppel K, Freedman NJ: The plateletderived growth factor receptor-beta phosphorylates and activates $G$ protein-coupled receptor kinase-2. A mechanism for feedback inhibition. J Biol Chem 2005, 280:31027-31035.

40. Irizarry RA, Hobbs B, Collin F, Beazer-Barclay YD, Antonellis KJ, Scherf U, Speed TP: Exploration, normalization, and summaries of high density oligonucleotide array probe level data. Biostatistics 2003, 4:249-264.

doi:10.1186/1476-4598-12-18

Cite this article as: Yuan et al:: Growth factor receptor-Src-mediated suppression of GRK6 dysregulates CXCR4 signaling and promotes medulloblastoma migration. Molecular Cancer 2013 12:18.

\section{Submit your next manuscript to BioMed Central and take full advantage of:}

- Convenient online submission

- Thorough peer review

- No space constraints or color figure charges

- Immediate publication on acceptance

- Inclusion in PubMed, CAS, Scopus and Google Scholar

- Research which is freely available for redistribution

Submit your manuscript at www.biomedcentral.com/submit
C Biomed Central 